\title{
Total Phenolic Contents and Antioxidant Variations in Raw and Cooked Dried Fruit of Xylopia aethiopica
}

\author{
Oso $\mathrm{BJ}^{1 *}$ and Oladiji $\mathrm{AT}^{2}$ \\ ${ }^{1}$ Department of Biochemistry, Kings University, Odeomu, Osun State, Nigeria \\ ${ }^{2}$ Department of Biochemistry, University of Ilorin, Ilorin, Kwara State, Nigeria \\ * Corresponding author email: basjoe08@gmail.com
}

Received: 09 August 2018 / Accepted: 23 September 2018 / Published: 02 October 2018

\begin{abstract}
Most plant products undergo one or more different thermal processes before consumption despite the claims that cooking fruits and vegetables could have detrimental effects on the beneficial properties of the plants. This work investigated the changes in antioxidant status occurring in dried fruit of Xylopia aethiopica subjected to cooking at different temperatures. The analyses were performed on both raw and boiled samples to assess the total phenolic contents (TPCs) and the antioxidant potential through reduction of ferric chloride salt and bleaching of 1,1-diphenyl-2-picrylhydrazyl (DPPH) radical. The data obtained were subjected to analysis of variance and pairwise comparisons by Tukey-Kramer test at $\mathrm{p}<0.05$. There was a significant heat-trend difference between the phenolic contents of the samples at the selected temperatures with the highest TPC recorded at $70^{\circ} \mathrm{C}$. Similarly, the ferric reducing potentials of the cooked samples were significantly different $(p<0.05)$ from the raw. However, uncooked samples had significantly $(\mathrm{p}<0.05)$ higher percentage of DPPH radical scavenging activity compared to cooked samples. The overall effect of cooking the dried fruit of $X$. aethiopica was due to an elevation in total phenolics concentrations and reducing potentials of the aqueous infusions. However, boiling decreases the DPPH radical scavenging ability of the samples. Therefore, this study suggests an optimum cooking temperature of $70^{\circ} \mathrm{C}$ which could result in the highest retention of phenolic contents and ferric reducing potentials in the fruit of $X$. aethiopica and lowest appropriate temperature to conserve its intrinsic radical-scavenging activity in order to assure a higher quality food for the maintenance of human health. Moreover, losses in the phenolic contents and antioxidant potential should be considered when the procedural temperature during processing is unalterable.
\end{abstract}

Keywords: Thermal treatment, Xylopia aethiopica, total phenolic contents, antioxidant capacity, temperature.

\section{Introduction}

It is generally believed that diets with high antioxidant capacities might enhance improved health status, and thus, references to 'healthy' diets have pointed to the consumption of fruit and vegetables, most especially when defined on the theme of antioxidant and sound health. Consequently, dietetic antioxidants in fruits and vegetables have been receiving attention from researchers due to their beneficial effects on human health. The benefits associated with the consumptions of fruits and vegetables are more than the basic nutrition and scrumptiousness as they have been related to be the ideal way of enhancing antioxidant status. This is because they are presumed to be rich in vitamins, minerals, enzymes, phenolics, flavonoids and essential oils which are implicit in providing desired health as antioxidant compounds [1]. Consequently, they are believed to reduce the risk of degenerative diseases such as cancer and cardiovascular disease [2]. However, there have been assertions by the 
raw foodists that cooking fruits and vegetables might lead to loss of beneficial components and thus advocating consumption of raw fruits and vegetables [3]. Even when these claims sound convincing, the reality is that some fruits and vegetables are cooked before intake. Xylopia aethiopica is an angiosperm belonging to the family Annonaceae. The fruit is commonly called Negro pepper and used as a spice in culinary preparations of local condiments. Several studies had documented the biological activities of the plant which include antioxidant [4], antimicrobial [5], anticancer [6], analgesic [7], anti-fungal [8], anti-inflammatory [9], anti-protozoan [10] and anti-allergic [11]. It must be noted that these earlier reports were largely obtained from uncooked samples. Likewise, the traditional and culinary use of $X$. aethiopica mostly requires thermal treatment with the intention of obtaining non-toxic, hygienic and high-quality food products with satisfactory sensory attributes. Therefore, this work investigated the changes in antioxidant occurring in dried fruit of $X$. aethiopica subjected to different cooking processes.

\section{Materials and Methods}

\subsection{Sample Preparation}

Dried fruits of $X$. aethiopica (100g) were powdered and divided into four separate portions. Three portions were boiled separately in $25 \mathrm{ml}$ of distilled water in a covered conical flask for 10 minutes at 50,70 and $90^{\circ} \mathrm{C}$. The remaining portion was immersed in $25 \mathrm{ml}$ of distilled water and extracted without boiling. The samples were filtered on WhatmanTM \#1.

\subsection{Estimation of Total Phenolic Content}

The total phenolic content (TPC) was estimated using the Folin-Ciocalteu method as described by Singleton et al. [12]. Exactly $1.0 \mathrm{ml}$ of FolinCiocalteu reagent solution $(1: 10 \mathrm{v} / \mathrm{v})$ was added to $0.5 \mathrm{ml}$ of each filtrate. The mixture was allowed to stand at room temperature of $30^{\circ} \mathrm{C}$ for 25 minutes. Afterward, $5 \mathrm{ml}$ of $7.5 \%$ sodium carbonate was added to the reaction mixture. After 20 minutes, the absorbance was measured at $725 \mathrm{~nm}$. The values were expressed in $\mathrm{mg} / 100$ g dried weight (DW).

\subsection{Ferric Reducing Antioxidant Potential (FRAP)}

The reducing potentials of the filtrates were determined as described by Oyaizu [13]. The sample $(0.5 \mathrm{ml})$ was mixed with $1.5 \mathrm{ml}$ of $0.1 \mathrm{M}$ sodium phosphate buffer ( $\mathrm{pH}$ 6.7) and $0.1 \mathrm{ml}$ of $1 \%$ potassium ferricyanide. The mixture was allowed to incubate at room temperature of $29^{\circ} \mathrm{C}$ for 30 minutes. Thereafter, $0.1 \mathrm{ml}$ of $5 \%$ trichloroacetic acid (TCA) was added to the reaction mixture. This mixture was centrifuged at $600 \times \mathrm{g}$ for 5 minutes. Subsequently, $2 \mathrm{ml}$ of the supernatant was mixed with an equal volume of water and $0.5 \mathrm{ml}$ of $0.1 \%$ ferric chloride and the absorbance was read at $700 \mathrm{~nm}$. The reducing antioxidant property was calculated using ascorbic acid as the standard and the result was expressed in mg per $100 \mathrm{~g}$ of the dried weight.

\subsection{DPPH Radical Scavenging Activity}

The ability of each of the filtrate to donate a hydrogen atom or an electron was determined through the bleaching of DPPH solution prepared in methanol as described by Shirwaikar et al. [14]. An aliquot of $1.50 \mathrm{ml}$ of the sample was added to $2 \mathrm{ml}$ of $0.001 \mathrm{M} \mathrm{DPPH}$ in methanol. Absorbance at $517 \mathrm{~nm}$ was measured after the reacting mixture had been left in the dark for 30 minutes. The percentage inhibition was calculated as follow:

$\%$ Inhibition $=\frac{\text { Absorbance of blank }- \text { Absorbance of sample }}{\text { Asorbance of blank }} \times 100$

\section{Results and Discussion}

Results from this study revealed that thermal treatment enhanced the availability of total phenolic contents (TPCs) (Table 1). However, boiling at $90^{\circ} \mathrm{C}$ resulted in significantly $(\mathrm{p}<0.05)$ lower TPC than that of boiling at $70^{\circ} \mathrm{C}$. Similarly, a study on antioxidant assessment based on the reduction of ferric salt showed that boiling significantly $(p<0.05)$ increased the reducing antioxidant potential of the sample compared with the raw sample. However, slight but nonsignificant differences were noted as the temperature changes with boiling at $70^{\circ} \mathrm{C}$ showing the highest reducing antioxidant potential (Figure 1). However, a significant reduction $(\mathrm{p}<0.05)$ in the radical scavenging 
Oso et al., Int. Ann. Sci.; Vol. 6, Issue 1, pp: 13-17, 2019

ability was observed after boiling compared with the raw filtrate (Figure 2).

Table 1: Total phenolic contents of the dried fruit of $X$. aethiopica after heat treatments at different temperature

\begin{tabular}{|l|l|l|}
\hline Temperature & TPC mg/100g DW & \% Increase in mean \\
\hline $50^{\circ} \mathrm{C}$ & $743.86 \pm 10.63^{\mathrm{a}}$ & 73.70 \\
\hline $70^{\circ} \mathrm{C}$ & $1801.38 \pm 1.88^{\mathrm{b}}$ & 320.64 \\
\hline $90^{\circ} \mathrm{C}$ & $702.00 \pm 20.00^{\mathrm{c}}$ & 63.92 \\
\hline Raw & $428.25 \pm 1.25^{\mathrm{d}}$ & - \\
\hline
\end{tabular}

Data are means \pm standard deviations of three determinations. Values with in a column with different superscripts differ significantly at $\mathrm{p}<0.05$

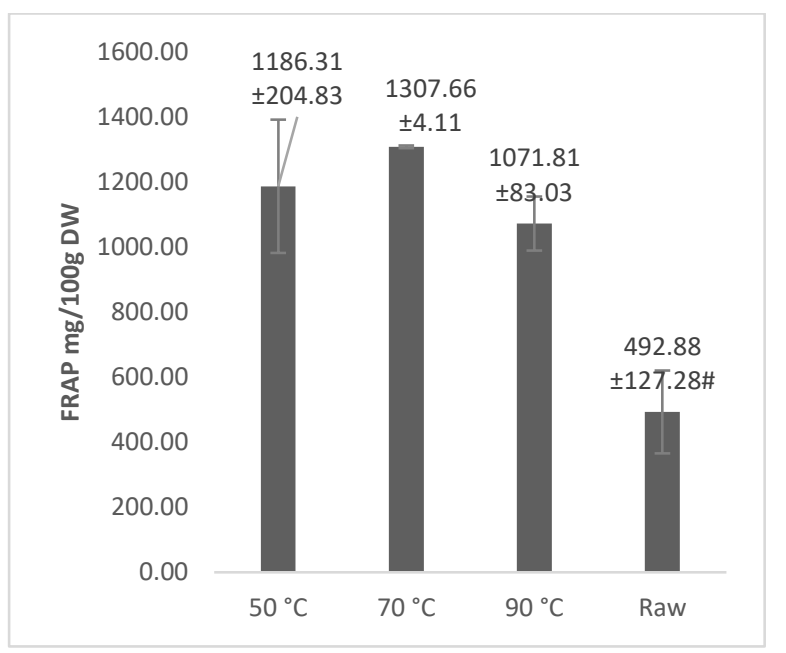

Figure 1: Effect of cooking on ferric reducing antioxidant potential of the dried fruit of $X$. aethiopica. Data are means \pm standard deviations of three determinations. \# represents significant difference at $p<0.05$.

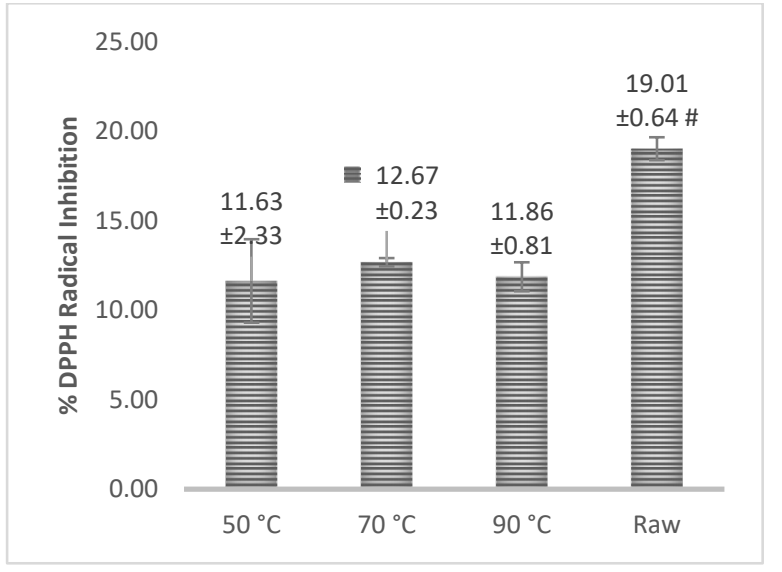

Figure 2: Effect of DPPH radical scavenging potential of the dried fruit of X. aethiopica. Data are means \pm standard deviations of three determinations. \# represents significant difference at $p<0.05$
There are several varieties of fruits and vegetables with varying degree of nutrients, antinutrients, anutrients, physicochemical properties, phytochemical components, fibrous contents and bioactivities. Even though some of these vegetables can be eaten raw, most of them undergo different cooking processes rather than being eaten raw. The proponents of raw foodism discourage cooking of fruits and vegetables ostensibly to retain the nutrients and the natural benefits of the vegetables for the reason that cooking decreases the bioavailability of nutrients as it enhances nutrient leaching into cooking water and also destroys heat- sensitive nutrients [3]. Consequently, thermal treatments of fruits and vegetables have thus been assumed to have a detrimental effect on their antioxidant values. Despite this advocacy, many tropical foods, especially spices, are usually consumed as cooked partly because culinary preparation of foods depends mostly on suitability and palate rather than nutrient value [15].

The present study revealed that the mean TPC increased after the sample was boiled. This observation is in agreement with the reports from other authors. Zambrano-Moreno et al. [16] reported significant increase in the total phenolic contents of eggplant after boiling. Equally short aquathermal treatment of five minutes at $80^{\circ} \mathrm{C}$ had been shown to have no detrimental effect on the total phenolic content of Pterocarpus mildbraedii and Celosia argentea, total flavonoid content and reducing power activity of Piper guineense but rather enhance the antioxidant value of the vegetables by increasing the bio-accessible phenolics and flavonoids [17]. The increase in the values of the TPC may be interconnected to increase in the liberation of phenolic compounds from the cellular matrix during the boiling process. This is because phenolic compounds are usually esterified with cell wall carbohydrates [18]. The enhancement of the total phenolic contents might invariably contribute to increase in the reducing power of the sample after cooking treatment. Besides, fat-soluble vitamins (A, D, E and $\mathrm{K}$ ), phenolics, lycopene, flavonoids and various micronutrients in plant which have been found to become more bioavailable by cooking could also contribute largely to the antioxidant 
potentials of the fruit with respect to reducing potentials [19, 20]. Moreover, Maillard reaction products formed during thermal treatments could also contribute to increased reducing potentials after cooking [21]. However, cooking at a temperature of $90^{\circ} \mathrm{C}$ could lead to the destruction of the leached antioxidant compounds at a higher temperature as observed in the current report. This is in agreement with report that some phytochemicals become unstable and decreased with increased time and temperature when exposed to a cooking temperature of $90^{\circ} \mathrm{C}$ [22]. Similarly, there are reports of the decrease in total phenolics and total antioxidant values of some selected cruciferous vegetables blanched at $98^{\circ} \mathrm{C}$ [23].

In addition, the redox potential of antioxidant compounds in the sample could be influenced by several reactions during cooking condition as cooking could enhance formation or destruction of metabolites with redox potentials [24]. The reduction in the radical scavenging potential after cooking could be attributed to the perceived transformations in the redox potential of the sample. The cooking condition in this present study might be severely extreme for the sample as there are reports that some methods of treatments such as steaming could increase the radical scavenging potentials of botanicals [25, 26]. Moreover, disruption of plant cell walls during thermal treatment could also lead to the release of oxidative and hydrolytic enzymes that could rescind the antioxidant potentials in the samples. It is thus recommended to employ mild thermal treatment in processing procedures that require the use of the fruit of $X$. aethiopica and the losses in the phenolic contents and antioxidant potential should be considered when the technical temperature during processing is requisite.

\section{Conclusion}

The present study concludes that phenolic contents and antioxidant potentials of $X$. aethiopica were affected by cooking. Boiling at temperature of $70^{\circ} \mathrm{C}$ increased the phenolic contents and the ferric reducing potential in the fruit. However, the total phenolic content decreased at higher temperature of $90^{\circ} \mathrm{C}$.
Additionally, the study revealed that cooking at the temperatures of 50,70 and $90^{\circ} \mathrm{C}$ could reduce the radical scavenging potentials in the fruit. Therefore, this study suggests an optimum cooking temperature, which could result in the highest retention of phenolic contents and ferric reducing potentials in the fruit of $X$. aethiopica and lowest appropriate temperature to conserve the radical-scavenging potential and assure a higher quality spice for the maintenance of human health.

\section{Declarations}

\subsection{Acknowledgements}

The authors appreciate the assistance of $\mathrm{Mr} \mathrm{BD}$ Olowookere, Biochemistry Laboratory, Kings University, Odeomu, Nigeria.

\subsection{Funding source}

None

\subsection{Competing interests}

The authors declared no potential conflict of interest exists.

\section{How to Cite this Article:}

B. Oso and A. Oladiji, "Total Phenolic Contents and Antioxidant Variations in Raw and Cooked Dried Fruit of Xylopia aethiopica", Int. Ann. Sci., vol. 6, no. 1, pp. 13-17, Oct. 2018. Doi: 10.21467/ias.6.1.13-17

\section{References}

[1] A. Rodriguez-Casado, "The health potential of fruits and vegetables phytochemicals: Notable examples," Critical Reviews in food Science and Nutrition, vol. 56, no. 7, pp. 1097-1107, 2014.

[2] C. Maritess, S. Small, and M. Waltz-Hill, "Alternative nutrition therapies in cancer patients," Sem. Oncol. Nurs., vol. 21, pp. 173-176, 2005.

[3] K. L. Brookie, G. I. Best and T. S. Conner, "Intake of raw fruits and vegetables is associated with better mental health than intake of processed fruits and vegetables," Front. Psychol., vol. 9, pp. 487, 2018.

[4] B. J. Oso, O. Oyeleke and O. Soetan, "Influence of different solvent polarities on the phenolics, flavonoids and antioxidant properties of the fruit of Xylopia aethiopica (Dunal) A. Rich.," Trends Phytochem. Res., vol. 2, no. 2, pp. 97-102, 2018.

[5] G. H. Konning, C. Agyare and B. Ennison, "Antimicrobial activity of some medicinal plants from Ghana," Fitoterapia, vol. 75, no. 1, pp. 65-67, 2004.

[6] O. A. Adaramoye, J. Sarkar, N. Singh, S. Meena, B. Changkija, P. P. Yadav, S. Kanojiya and Sinha S, "Antiproliferative action of Xylopia aethiopica fruit extract on human cervical cancer cells," Phytotherapy Research., vol. 25, no. 10, pp. 1558-1563, 2011. 
Oso et al., Int. Ann. Sci.; Vol. 6, Issue 1, pp: 13-17, 2019

[7] E. O. Ameyaw, E. Woode, E. Boakye-Gyasi, W. K. Abotsi, J. O. Kyekyeku and R. K. Adosraku, "Anti-allodynic and Anti-hyperalgesic effects of an ethanolic extract and xylopic acid from the fruits of Xylopia aethiopica in murine models of neuropathic pain," Pharmacognosy Research, vol. 6, no. 2, pp. 172-179, 2014.

[8] S. L. Sado Kamde, N. Belletti, F. Tchoumbougnang, J. J. Essia-Ngang, C. Montanari, G. Tabanelli, R. Lanciotti and F. Gardini, "Effect of mild heat treatments on the antimicrobial activity of essential oils of Curcuma longa, Xylopia aethiopica, Zanthoxylum xanthoxyloides and Zanthoxylum leprieurii against Salmonella enteritidis," Journal of Essential Oil Research, vol. 27, no.1, pp. 52-60, 2015.

[9] B. J. Oso, E. B. Oyewo and A. T. Oladiji, "Ethanolic, nhexane and aqueous partitioned extracts of Xylopia aethiopica fruit modulated inflammatory responses in turpentine oil induced acute inflammation in male Wistar rats," Int. J. Res. Health Sci., vol. 5, no. 2, pp. 1-10, 2017.

[10] F. F. Boyom, V. Ngouana, P. H. Zollo, C. Menut, J. M. Bessiere, J. Gut and P. J. Rosenthal, "Composition and antiplasmodial activities of essential oils from some Cameroonian medicinal plants," Phytochemistry, vol. 64, no. 7, pp. 1269-1275, 2003.

[11] D. D. Obiri and N. Osafo, "Aqueous ethanol extract of the fruit of Xylopia aethiopica (Annonaceae) exhibits antianaphylactic and anti-inflammatory actions in mice," Journal of Ethnopharmacology, vol. 148, no. 3, pp. 940945, 2013.

[12] V.L. Singleton, R. Orthofer and R.M. Lamuela-Raventos, "Analysis of total phenols and other oxidation substrates and antioxidants by means of Folin-Ciocalteu reagent," Methods Enzymol., vol. 299, pp. 152-178, 1999.

[13] M. Oyaizu, "Studies on products of browning reactions: antioxidant activities of products of browning reaction prepared from glucosamine," Jap J Nutr., vol. 44, pp. 307315, 1986.

[14] A. Shirwaikar, K. Rajendran and I. S. Punithaa, "In vitro antioxidant studies on the benzyl tetra isoquinoline alkaloid berberine," Biological and Pharmaceutical Bulletin, vol. 29, pp. 1906-1910, 2006.

[15] M. A. Masrizal, D. W. Giraud and J. A. Driskell, "Retention of vitamin $\mathrm{C}$, iron, and beta-carotene in vegetables prepared using different cooking methods," J. Food Qual., vol. 20, no. 5, pp. 403-418, 1997.

[16] E. L. Zambrano-Moreno, R. N. Chávez-Jáuregui, M. I. Plaza and L. Wessel-Beaver, "Phenolic content and antioxidant capacity in organically and conventionally grown eggplant (Solanum melongena) fruits following thermal processing," Food Sci. Technol, Campinas, vol. 35, no. 3,pp. 414-420, 2015.

[17] S. O. Nwozo, B.J. Oso and B. E. Oyinloye, "Effect of Heat on Antioxidant Activity of Some Tropical Leafy Vegetables," Nigerian Journal of Basic and Applied Science, vol. 23, no. 2, pp. 93-101. 2015.

[18] B. Harbaum, E. M. Hubbermann, C. Wolff, R. Herges, Z. Zhu and K. Schwarz, "Identification of Flavonoids and Hydroxycinnamic Acids in Pak Choi Varieties (Brassica campestris L. ssp. chinensis var. communis) by HPLCESI-MS $\mathrm{n}$ and NMR and Their Quantification by HPLCDAD," J. of Agricultural and Food Chemistry, vol. 55, no. 20, pp 8251-8260, 2007.

[19] B. Simone and E. Schlich, "Impact of different cooking methods on food quality: Retention of lipophilic vitamins in fresh and frozen vegetables," Journal of Food Engineering, vol. 77, pp. 327-333, 2006.
[20] H. D. Mistry and P. J. Williams, "The importance of antioxidant micronutrients in pregnancy," Oxidative Medicine and Cellular Longetivity, vol. 2011, pp. 841749, 2011.

[21] L. N. Vhangani and J. Van Wyk, "Antioxidant activity of Maillard reaction products (MPRs) in a lipi-rich model system," Food Chem., vol. 208, pp. 301-308, 2016.

[22] M. Mayeaux, Z. Xu, J. M. King, W. Prinyawiwatkui, "Effects of Cooking Conditions on the lycopene content in tomatoes," J. Food Science, vol. 71, no. 8, pp. C461-C464, 2006.

[23] I. Amin and W. Y. Lee, "Effect of different blanching times on antioxidant properties in selected cruciferous vegetables," J. Sci. Food Agric., vol. 85, pp. 2314-2320, 2005.

[24] A. Ruiz-Rodriguez, F. R. Marín, A. Ocaña and C. SolerRivas, "Effect of domestic processing on bioactive compounds," Phytochemistry Review, vol. 7, pp. 345-384, 2008.

[25] S. A. Adefegha and G. Oboh, "Enhancement of total phenolics and antioxidant properties of some tropical green leafy vegetables by steam cooking," Journal of Food Processing and Preservation, vol. 35, no. 5, pp. 615-622, 2011.

[26] N. D Thi, and E. S. Hwang, "Effects of different cooking methods on bioactive compound content and antioxidant activity of water spinach (Ipomoea aquatica)," Food Science and Biotechnology, vol. 24, no. 3, pp. 799-806, 2015.

\section{Publish your research article in AIJR journals- \\ $\checkmark \quad$ Online Submission and Tracking \\ $\checkmark$ Peer-Reviewed \\ $\checkmark \quad$ Rapid decision \\ $\checkmark \quad$ Immediate Publication after acceptance \\ $\checkmark \quad$ Articles freely available online \\ $\checkmark \quad$ Retain full copyright of your article. \\ Submit your article at journals.aijr.in}

\section{Publish your books with AIJR publisher- \\ $\checkmark \quad$ Publish with ISBN and DOI. \\ $\checkmark \quad$ Publish Thesis/Dissertation as Monograph. \\ $\checkmark \quad$ Publish Book Monograph. \\ $\checkmark \quad$ Publish Edited Volume/ Book. \\ $\checkmark \quad$ Publish Conference Proceedings \\ $\checkmark \quad$ Retain full copyright of your books. \\ Submit your manuscript at books.aijr.org}

